\title{
Upper gastrointestinal findings detected by capsule endoscopy in obscure gastrointestinal bleeding
}

\author{
B. Velayos, A. Herreros de Tejadaํ, L. Fernández, R. Aller, A. Almaraz², L. del Olmo, F. de la Calle, \\ T. Arranz and J. M. González
}

Service of Digestive Diseases. Hospital Clínico de Valladolid. Spain. ${ }^{1}$ Center for Endoscopic Research and Therapeutics. Universidad de Chicago. U.S.A. ${ }^{2}$ Service of Preventive Medicine. Hospital Clínico de Valladolid. Spain

\begin{abstract}
Objective: we analyzed our experience with the use of capsule endoscopy in areas that can be explored with gastroscopy to justify obscure bleeding, as well as the outcome after a new recommended gastroscopy in order to determine if a second gastroscopy before the capsule study can provide any benefit in the management of this disease.

Methods: we retrospectively studied 82 patients who were explored with capsule endoscopy for obscure gastrointestinal bleeding who had undergone previously only one gastroscopy.

Findings in the zones which were accessible by gastroscopy were normal, mild/known and severe/unknown. In the latter cases we recommended a second gastroscopy, and their treatment and outcome were subjected to further study.

Results: capsule endoscopy did not find any unknown esophageal findings. In $63 \%$ of cases, no gastric or duodenal lesions were shown; in 20\%, lesions were mild or had been previously diagnosed, and in $17 \%$, a new gastroscopy was recommended due to the discovery of an unknown condition which could be the cause of the obscure bleeding. This new information brought about a change in treatment for $78 \%$ of patients in this group, all of whom improved from their illness. Capsule endoscopy found significant intercurrent alterations in the small intestine in only $14 \%$ of cases.

Conclusions: the performance of a second gastroscopy, previous to capsule endoscopy, in the study of obscure gastrointestinal bleeding can offer benefits in diagnostic terms and may introduce therapeutic changes.

A detailed analysis of the upper tract frames in intestinal capsule endoscopy studies is mandatory since it may provide relevant information with clinical impact on the management of these pa-
\end{abstract} tients.

Key words: Capsule endoscopy. Obscure gastrointestinal bleeding. Gastroscopy.

Received: $14-07-08$

Accepted: 10-11-08.

Correspondence: Benito Velayos Jiménez. Servicio de Aparato Digestivo. Hospital Clínico de Valladolid. Avda. Ramón y Cajal, 3. 47005 Valladolid.Spain.e-mail: benitovelayos@hotmail.com
Velayos B, Herreros de Tejada A, Fernández L, Aller R, Almaraz A, del Olmo L, de la Calle F, Arranz T, González JM. Upper gastrointestinal findings detected by capsule endoscopy in obscure gastrointestinal bleeding. Rev Esp Enferm Dig 2009; 101: 11-19.

\section{INTRODUCTION}

Obscure gastrointestinal bleeding (OGIB) accounts for up to $5-8 \%$ of all causes of digestive bleeding $(1,2)$, and represents one of the main indications for intestinal wireless capsule endoscopy (WCE) (3-5). To formulate a preliminary diagnosis of OGIB (either overt or occult) according to the established definition, at least one diagnostic esophageal gastroduodenoscopy (EGD) and colonoscopy should have been performed (6). Although some published algorithms even suggest a repeat upper endoscopy before submitting the patient for WCE to complete the study of the small bowel (7), some authors postulate that the final decision should rely either on the preferences of the endoscopist performing the first EGD (8) or according to the findings of WCE once completed (9). This latter statement has been supported by results from some retrospective studies published in the last few years $(10,11)$.

On the other hand, some common diseases, which can be cause of chronic anemia -e. g. severe gastroesophageal reflux (12) or esophageal varices screening in cirrhosis (13)-, usually require a repeat EGD (14). Performance of a repeat EGD is sometimes a matter of discussion with the patient, who might eventually reject this practice (15).

It is common to incidentally discover new findings in the gastrointestinal tract proximal to the second portion of the duodenum while performing WCE for OGIB (16) (17). These findings may be relevant enough either in 
terms of therapeutic decisions or cost-effectiveness (17).

Our aim was to evaluate the clinical impact of repeat upper endoscopy after an initially negative procedure in patients with OGIB in terms of its role in reducing unnecessary WCE studies.

\section{PATIENTS AND METHODS}

We designed a descriptive retrospective study to identify pathologic findings in the regions considered within range of a standard EGD examination in patients referred to our center for WCE in case of OGIB (occult and overt) with a normal initial EGD. Patients with esophageal, gastric or duodenal abnormalities - proximal to the ampulla of Vater (18) - were recommended a new EGD. Baseline characteristics, new endoscopic findings, and follow-up of recruited patients were recorded, and a posterior analysis was carried out.

Clinical information on every patient was retrieved from the clinical report of the referring doctor. In case of missing data, the referring doctor was contacted via phone or fax. Information about symptoms of the upper digestive tract in the last month was obtained in person, on the day of WCE, including pyrosis, regurgitation and acute epigastric abdominal pain. Daily medication informations were obtained, paying particular attention to antiplatelet therapies, anticoagulants, proton-pump inhibitors (PPIs), non-steroidal anti-inflammatories (NSAIDs), and muscle-relaxants such as beta-adrenergic and alpha-adrenergic antagonists, calcium-channel antagonists, anticholinergics, contraceptives, benzodiazepines, nitrates, opiates, and xanthine. Smoking at least 10 cigarettes a day, and drinking over 20 grams of alcohol a day were the thresholds used for the definition of "tobacco" and "alcohol" use/intake, respectively.

Inclusion criteria included a prior and unique EGD 1 to 12 weeks before the day of the WCE study.

Our endoscopy section is a referral unit for WCE in the region of Castile \& Leon, comprising a total of 2.5 million inhabitants. Requesting forms were submitted mainly by gastroenterologists, followed by internists, surgeons, and hematologists.

We used the same protocol for WCE in all patients, which excluded the use of any prokinetics or preparations of the intestine using cleaning solutions. The WCE system used was a Given Imaging M2A plus ${ }^{\circledR}$ with spatial location through 7 sensors placed in the abdomen, and the recording system was a Data Recorder TM Given ${ }^{\circledR}$. The "M2A plus ${ }^{\circledR}$ " capsule was swallowed by the patient with the help of less than $30 \mathrm{cc}$ of water. This capsule is $26 \times 11 \mathrm{~mm}$ in size and 3.45 gram in weight. The preparation for the procedure included a fasting period of at least 4 hours, except for some clear liquids. After swallowing the capsule, patients were suggested to walk as much as possible. The display of recorded data took place on the same week of the exploration and was performed by three doctors, all of them experimented in the technique.

The report was written using the standard, accepted terminology (19).

After WCE results, new upper digestive tract findings were noted (known abnormalities from prior EGD were excluded). Particular attention was paid to those cases in which the newly discovered lesions were located within the anatomic range of a standard EGD evaluation, and could possibly justify the origin of OGIB. Some examples were severe esophagitis, large esophageal varices, erosive gastritis or duodenitis with blood, significant vascular lesions, severe portal gastropathy, gastric or duodenal ulcers, and neoplastic lesions).

In any of these cases, even if a small-bowel alteration had been also observed during the WCE exam, a repeat EGD was recommended to the referring doctor. The completion of a repeat EGD was then confirmed by means of contacting the patient or referring doctor via a phone call. Any information obtained in the repeated EGD was registered, as well as new therapeutic orders and clinical follow-up.

\section{RESULTS}

In a period of two years, we prospectively studied 82 patients (49 men and 33 women). Their mean age was 61.3 years (range 28-83). The prevalence of alcohol consumption and smoking was 10 and $12 \%$, respectively. Concerning the use of medications in this population, this was led by PPIs (52\%) followed by muscular relaxants (41\%), antiplatelet drugs (17\%), and anticoagulants (7\%). No patient used non-steroidal anti-inflammatory drugs. Only in $15 \%$ of these patients complained about upper gastrointestinal symptom.

All initial EGDs were normal or with a diagnosis that did not explain bleeding (small hiatal hernias, mild esophagitis, I-II/IV esophageal varices, mild portal hypertension associated gastropathy, esophageal papillomas, or non-eroded gastric polyps).

The average time recorded in the esophagus and stomach for the capsule was 35 minutes (range 1-142 minutes).

In the esophagus, we clearly recognized small esophageal varices and papillomas, but we could not identify mild esophagitis or hiatal hernias. WCE did not show any new esophageal findings.

WCE results showed no gastroduodenal lesions in 52 (63\%) patients. In 16 cases $(20 \%)$, some already diagnosed or new minor unimportant lesions (slight erosive gastro-duodenitis, slight gastric portal gastropathy, and non-eroded small polyps) were observed. In the remaining $14(17 \%)$ patients, WCE showed relevant gastric and/or duodenal lesions not previously noted during initial EGD (Table I). Mean age in this group was 70 years (range: $22-80$ ). Male proportion was $71.4 \%$; the use of PPIs $(57 \%)$ and antiplatelets $(21 \%)$ was also increased in 
Table I. Patients with upper tract bleeding diagnosed by capsule endoscopy, second EGD findings, and follow-up

\begin{tabular}{|c|c|c|c|c|c|c|c|c|}
\hline Case & Age & Sex & Antiplatelets & PPls & $\begin{array}{l}\text { WCE diagnosis in } \\
\text { upper tract }\end{array}$ & Second EGD & $\begin{array}{l}\text { Findings in the SB } \\
\text { in WCE }\end{array}$ & Evolution \\
\hline 1 & 80 & $\mathrm{M}$ & No & Yes & $\begin{array}{c}\text { Inflammatory and } \\
\text { hemorrhagic gastropathy }\end{array}$ & Not performed & WCE uncompleted & $\begin{array}{l}\text { Asymptomatic with } \\
\text { double dose of PPIs }\end{array}$ \\
\hline 2 & 47 & $\mathrm{M}$ & No & No & Hemorrhagic gastritis & Not performed & SB normal & Asymptomatic with PPIs \\
\hline 3 & 74 & $\mathrm{~F}$ & No & Yes & Hemorrhagic gastritis & Not performed & SB normal & $\begin{array}{l}\text { Asymptomatic with double } \\
\text { dose of PPIs }\end{array}$ \\
\hline 4 & 59 & $M$ & No & No & Hemorrhagic gastritis & Not performed & SB normal & Asymptomatic with PPIs \\
\hline 5 & 53 & M & No & No & Hemorrhagic gastritis & $\begin{array}{l}\text { Yes. It did not confirm } \\
\text { WCE findings. } \\
\text { EGD performed } 2 \text { weeks } \\
\text { after WCE }\end{array}$ & Slight enteropathy & $\begin{array}{c}\text { Still in study. } \\
\text { Asymptomatic with PPIs }\end{array}$ \\
\hline 6 & 80 & M & No & Yes & Hemorrhagic gastritis & Not performed & Vascular lesions in SB & $\begin{array}{l}\text { Dead secondary to } \\
\text { massive bleeding. }\end{array}$ \\
\hline 7 & 70 & $\mathrm{M}$ & No & Yes & $\begin{array}{l}\text { Duodenal and gastric } \\
\text { vascular lesion }\end{array}$ & Yes. It discovered gastric tumor & SB normal & Asymptomatic after surgery \\
\hline 8 & 79 & M & AA & Yes & Duodenal ulcer & Not performed & SB normal & Dead (unknown cause) \\
\hline 9 & 22 & $\mathrm{M}$ & No & No & Duodenal ulcer & Not performed & SB normal & Asymptomatic with PPIs \\
\hline 10 & 59 & $\mathrm{M}$ & No & Yes & Tumoral stenosis in duodenum & $\begin{array}{l}\text { Yes. } \\
\text { It confirmed WCE findings }\end{array}$ & $\begin{array}{l}\text { WCE did not go through } \\
\text { the stenosis }\end{array}$ & Asymptomatic after surgery \\
\hline 11 & 76 & $\mathrm{~F}$ & No & No & Inflamatory duodenal stenosis & $\begin{array}{c}\text { Yes. } \\
\text { It confirmed WCE findings }\end{array}$ & $\begin{array}{c}\text { Several ulcers and areas } \\
\text { of marked lymphoid } \\
\text { hyperplasia }\end{array}$ & $\begin{array}{l}\text { Diagnosis of intestinal } \\
\text { lymphoma. } \\
\text { Surgical and oncologic therapy }\end{array}$ \\
\hline 12 & 72 & $\mathrm{M}$ & No & No & Gastric vascular lesion & $\begin{array}{l}\text { Yes. } \\
\text { It confirmed WCE findings }\end{array}$ & SB normal & $\begin{array}{c}\text { Asymptomatic after argon and } \\
\text { PPls }\end{array}$ \\
\hline 13 & 77 & $\mathrm{~F}$ & AA & Yes & Watermelon stomach & $\begin{array}{c}\text { Yes. } \\
\text { It confirmed WCE findings }\end{array}$ & SB normal & $\begin{array}{l}\text { Clinical improvement after } \\
\text { argon-beam therapy }\end{array}$ \\
\hline 14 & 75 & $\mathrm{~F}$ & AA + clopidogrel & Yes & Watermelon stomach & $\begin{array}{c}\text { Yes. } \\
\text { It confirmed WCE findings }\end{array}$ & $\begin{array}{l}\text { Only one unlikely } \\
\text { microerosion in jejunum }\end{array}$ & $\begin{array}{c}\text { Poor response to argon-beam } \\
\text { therapy }\end{array}$ \\
\hline
\end{tabular}

PPIs: proton pump inhibitors; WCE: capsule endoscopy; SB: small bowel; AA: acetilsalicilic acid; EGD: esophago-gastro-duodenoscopy.

comparison with the rest of the study population. Tobacco consumption was similar to the total population average $(14 \%)$, and no case of alcohol use was observed. Of note, none of these patients reported any upper gastrointestinal tract symptoms. There were no significant differences in time intervals between EGD and WCE in this group with regard to the rest of patients.

In 8 of these 14 patients, gastro-duodenal lesions were the only pathological findings discovered in the digestive tract. In the remaining 4 patients (patient's number 1 and 10 did not complete WCE), we observed lesions in the small bowel, but in only two of them with an entity that could explain the source of OGIB.

A new EGD was performed in 7 patients (7 refused). In $86 \%$ of them WCE findings were confirmed (Table I).

\section{DISCUSSION}

WCE has become one of the most important non-invasive diagnostic tests for the evaluation of the small bowel (20). Due to its straightforward procedural application and few complications, WCE is widely accepted by patients, in contrast to other procedures such as
EGD (21). On the other hand, EGD is the most accurate endoscopic procedure for detecting and treating most diseases of the upper digestive tract. It is a safe and usually well tolerated technique that has a high diagnostic yield (22-24).

Since 2002, WCE has been considered a complementary tool in the study of the upper gastrointestinal tract $(25,26)$. Of note, a new esophageal capsule endoscopy has been recently developed $(27,28)$. Some studies show that this esophageal capsule and EGD can be quite concordant in their findings, and ECE can even discover abnormalities not revealed by EGD $(29,30)$. The absence of gastric distension (among other reasons) makes capsule endoscopy a restricted procedure for the standard study of the stomach. However, technical improvements are promising, like those achieved in the colon (31).

WCE is an useful tool in the workup of OGIB, but certain issues, such as the limited effectiveness of medical therapies (32), development of new alternative endoscopic methods (double-balloon enteroscopy), and risk of capsule impaction (1.9\%) during WCE (33) suggest that new prospective studies are needed to clarify the most effective strategy in the evaluation of OGIB (34). Some studies have addressed the importance of repeat EGD be- 
fore recommending WCE. Other authors recommend a second EGD when WCE was normal (35).

Our group has tried to confront the question of the clinical impact of repeat EGD during workup for OGIB in our local population. Due to technical and ethical limitations (performing a repeat EGD just before WCE was not considered in our institution), our results have some limitations.

All the raised lesions observed in the esophagus during the first EGD were confirmed by WCE. According to Sharma et al., this single fact would support the inclusion of capsule endoscopy in the diagnostic armamentarium for the esophagus (28). New design features in ECE will provide a complete view of the esophageal lumen, obtaining a superior number of frames from other sites like the cardia (3638). Our results show that, although with some limitations in the identification of mild esophagitis and the cardia, WCE results allowed us to not recommend repeat EGD.

When considering our results in the stomach and duodenum, WCE was able to capture images for an average of 30 minutes, similar to data obtained in prior studies in the same population (39), but less than reported recently (40). Despite the technical limitations of WCE to evaluate the stomach and the duodenum, it provided information in 30 patients (37\%): 14 without a previous diagnosis and 16 with mild lesions previously diagnosed during the first EGD. These findings were considered significant enough to explain OGIB and recommend repeat EGD in 14 patients $(17 \%)$. In 8 cases, the gastro-duodenal findings observed during WCE were the only identifiable abnormalities in the digestive tract to explain the origin of bleeding. So we propose that performing a second EGD might have prevented the need for WCE in these cases. Although the prevalence of gastric and duodenal lesions in our local population diagnosed with OGIB is slightly superior to other series, the results are similar enough to make them consistent with present literature references $(10,11,41,42)$. In our country other studies with WCE have shown gastro-duodenal lesions in $3.4-9 \%$ of subjects $(43,44)$.

In only 2 patients, we found synchronous bleeding lesions in the upper tract and the small intestine, which prevented us from correlating these pathologies and attributing them to interactive or systemic factors.

Some of the limitations of this study are the possible different skills set between endoscopists performing initial and second EGDs (8), time interval between procedures, the possibility of intercurrences (45), the population heterogeneity considered for OGIB (46), and discrepancy between WCE accuracies according to OGIB type (47). The different time intervals between tests (due to the waiting list) can be an important limitation too, although, in most cases, it was between two and eight weeks. On the other hand, we are aware of the value of our study would achieve in case we would performed a second EGD procedure to the entire group on the same day of WCE. For us, it was impossible to carry out. How- ever, in our opinion, our results are relevant and reportable; WCE discovered significant lesions in areas accessible to standard EGD in a considerable number of patients (14/82), particularly in those with antiplatelet treatment; these being in 8 of them the only abnormality found. We think that performing a second EGD might have prevented the need for WCE in these cases.

These results did have a clinical impact on the diagnostic and therapeutic strategies for twelve patients. Of these twelve patients, six were diagnosed with peptic disease (not confirmed in the only one who underwent a second EGD) and their treatment was modified either by starting therapy with PPIs or by increasing prior doses with good results. Six patients with neoplastic or vascular lesions underwent a second EGD, and in all of them the WCE diagnosis was confirmed. Surgical or endoscopical therapy was decided according to those findings. Five of these six cases improved.

Although the detailed analysis of the stomach and duodenum using WCE provided benefit in our patients, we think that one of the most relevant points to improve the cost-benefit of this test in OGIB is a right indication, using it only after a rigorous exam of the mucosa during the initial EGD (and repeating it if necessary).

In conclusion, performing a second EGD before indicating a WCE study may increase the diagnostic yield and improve the cost-effectiveness of WCE in patients with OGIB. These findings would probably be enough to establish a final diagnosis, since the rate of synchronic bleeding-source lesions in the upper tract and the small bowel has proven quite low. A detailed, careful analysis of the upper tract frames from WCE is therefore recommended, since it may provide relevant new diagnostic information.

\section{ACKNOWLEDGEMENTS}

We are grateful to Felix Lozano for his work and help.

\section{REFERENCES}

1. American Gastrointestinal Association medical position statement: Evaluation and management of occult and obscure gastrointestinal bleeding. Gastroenterology 2000; 118: 197-200.

2. Dulai GS, Jensen DM. Severe gastrointestinal bleeding of obscure origin. Gastrointest Endosc Clin N Am 2004; 14(1): 101-13.

3. Rey JF, Ladas S, Alhassani A, Kuznetsov K: and the ESGE Guidelines Committee. European Society of Gastrointestinal Endoscopy (ESGE). Video capsule endoscopy: update to guidelines (May 2006). Endoscopy 2006; 10(38): 1047-53.

4. Mata A, Llach J, Bordas JM, Feu F, Pellisé M, Fernández-Esparrach $\mathrm{G}$, et al. Papel de la cápsula endoscópica en los pacientes con hemorragia digestiva de origen indeterminado. Gastroenterol Hepatol 2003; 26: 619-23.

5. Tang SJ, Haber GB. Capsule endoscopy in obscure gastrointestinal bleeding. Gastrointest Endsoc Clin N Am 2004; 14: 87-100.

6. AGA technical review on the evaluation and management of occult and obscure gastrointetinal bleeding. Gastroenterology 2000; 118: 201-21. 
7. Pennazio M, Eisen G, Goldfarb N. ICCE Consensus for Obscure Gastrointestinal Bleeding. Endoscopy 2005; 37: 1046-50

8. Cos E, González C, Menchén L, Núñez O, Ponferrada A, Menchén Fernández P. Hemorragia digestiva y cápsula endoscópica. En: Cos Arregui E, editor. Estado actual de la cápsula endoscópica. Barcelona: Editorial Glosa, S.L.; 2004. p. 41-7.

9. Gay G, Delvaux M, Fassler I. Outcome of capsule endoscopy in determining indication and route for push and pull enteroscopy. Endoscopy 2006; 38(1): 49-58

10. Peter S, Heuss LT, Beglinger C, Degen L. Capsule endoscopy of the upper gastrointestinal tract. The need for a second endoscopy. Digestion 2005; 72(4): 242-7.

11. Delvaux M, Fassler I, Gay G. Clinical usefulness of the endoscopic video capsule as the inicial intestinal investigation in patients with obscure digestive bleeding: validation of a diagnostic strategy based on the patient outcome alter 12 months. Endoscopy 2004; 36(12): 1067-73.

12. Sonnenberg A, El-Serag HB. Clinical epidemiology and natural history of gastroesophageal reflux disease. Yale J Biol Med 1999; 72: 81-92.

13. Ramirez FC, Hakim S, Tharalson EM, Shaukat MS, Akins R. Feasibility and safety of string wireless capsule endoscopy in the diagnosis of esophageal varices. Am J Gastroenterol 2005; 100(5): 1065-71.

14. Tang SJ, Zanati S, Kandel G, Marcon NE, Kortan P. Gastric intestinal vascular ectasia syndrome: findings on capsule endoscopy. Endoscopy $2005 ; 37(12)$ : 1244-7.

15. Sánchez A, Caunedo A, Romero R, Romero J, Antúnez A, Pellicer F, et al. Esophageal tumor diagnosed by capsule endoscopy. Endoscopy 2006; 38: 765

16. Mascareñas-Saraiva M, Lopes L, Mascareñas-Saraiva A. Watermelon stomach seen by wireless-capsule endoscopy. Endoscopy 2003; 35(1): 100 .

17. Kitiyakara T, Selby W. Non-small-bowel lesions detected by capsule endoscopy in patients with obscure GI bleeding. Gastrointest Endosc 2005; 62(2): 234-8

18. Ell C, May A. Mid-gastrointestinal bleeding: capsule endoscopy and push-and-pull enterocopy give rise to a new medical term. Endoscopy 2006; 38(1): 73-5.

19. Korman LY, Delvaux M, Gay G, Hagenmuller F, Keuchel M, Friedman S, et al. Capsule endoscopy structured terminology (CEST): proposal of a standardized and structured terminology for reporting capsule endoscopy procedures. Endoscopy 2005; 37(10): 951-9 (February 16, 2002 (C) Given Imaging Ltd).

20. Lewis BS, Eisen GM, Friedman S. A pooled analysis to evaluate results of capsule endoscopy trials. Endoscopy 2005; 37: 960-65.

21. Velayos B, Fernández L, Aller R, De la Calle F, Del Olmo L, Arranz $\mathrm{T}$, et al. Public opinion survey after capsule endoscopy: patient's point of view on its utility. Rev Esp Enferm Dig 2006; 98(6):436-48.

22. Esrailian E, Gralnek IM. Nonvariceal upper gastrointestinal bleeding: epidemiology and diagnosis. Gastroenterol Clin North Am 2005; 34(4): 589-605.

23. Calvet X, Vergara M, Brullet E. Endoscopic treatment of bleeding ulcers: has everything been said and done? Gastroenterol Hepatol 2005; 28(6): 347-53.

24. Sampliner RE. Practice Parameters Committee of the American Collage of Gastroenterology. Updated guidelines for the diagnosis, surveillance, and therapy of Barrett's esophagus. Am J Gastroenterol 2002; 97: 1888-95.

25. Balanzó J, González B, Sainz S. Cápsula endoscópica: presente y futuro. Gastroenterol Hepatol 2002; 25: 251-3.

26. Fleischer DE. Capsule endoscopy: the voyage is fantastic -will it change what we do? Gastrointest Endosc 2002; 56: 452-6.

27. Sánchez A, Caunedo A, García JM, Romero J, Pellicer FJ, Herrerías JM. Esophageal capsule endoscopy in patients refusing conventional endoscopy for the study of suspected esophageal pathology. Eur J Gastroenterol Hepatol 2006; 18(9): 977-83

28. Sharma VK, Eliakim R, Sharma P, Faigel D. ICCE Consensos for Esophageal Capsule Endoscopy. Endoscopy 2005; 37: 1060-4.

29. Eliakim R, Yassin K, Shlomi I, Suissa A, Eisen GM. A novel diagnostic tool for detecting esophageal pathology: the PillCam esophageal video capsule. Aliment Pharmacol Ther 2004; 20: 1083-9.
30. Eliakim R, Sharma VK, Yassin K, Adler SN, Jacob H, Cave DR, et al. A prospective study of the diagnostic accuracy of Given esophageal capsule endoscopy versus convencional upper endoscopy in patients with chronic gastroesophageal reflux diseases. J Clin Gastroenterol 2005; 39(7): 572-8.

31. Eliakim R, Fireman Z, Gralnek IM, Yassin K, Waterman M, Kopelman Y, et al. Evaluation of the PillCam Colon capsule in the detection of colonic pathology: results of the first multicenter, prospective, comparative study. Endoscopy 2006; 38: 963-70.

32. Molina Infante J, Pérez Gallardo B, Fernández Bermejo M. Avances en el tratamiento médico de la hemorragia digestiva de origen oscuro. Rev Esp Enferm Dig 2007; 99(8): 457-62.

33. Rondonotti E, Herrerías JM, Pennazio M, Caunedo A, MascareñasSaraiva M, de Francis R. Complications, limitations, and failures of capsule endoscopy: a review of 733 cases. Gastrointest Endosc 2005; 62(5): 712-6.

34. Pennazio M. Bleeding update. Gastrointest Endosc Clin N Am 2006; 16(2): 251-66). (Rey JF, Ladas S, Alhassani A, Kuznetsov K: and the ESGE Guidelines Committee. European Society of Gastrointestinal Endoscopy (ESGE). Video capsule endoscopy: update to guidelines (May 2006). Endoscopy 2006; 10 (38): 1047-53).

35. Caunedo Álvarez A, Rodríguez-Téllez M, Barroso Relinque N, García Montes JM, Pellicer Bautista FJ, Herrerías Gutiérrez JM. Papel de la cápsula endoscópica en el manejo del paciente con hemorragia digestiva de origen oscuro. Rev Esp Enferm Dig 2002; 94(8): 48292 .

36. Lin O, Kozarek RA, Schembre D, Spaulding W. Blinded comparison of esophageal capsule endoscopy (ECE) versus conventional esophago-gastroduodenoscopy (EGD) for identification of esophagitis and Barrett's esophagus in patients with chronic gastroesophageal reflux disease (GERD). In: Proceedings of the 4th International Conference on Capsule Endoscopy, Miami, Florida, 2005. Yoqneam, Israel: Given Imaging, 2005: AB74.

37. Eisen GM, Eliakim R, Zaman A, Schawartz J, Faigel D, Rondonotti E, et al. The accuracy of PillCam ESO capsule endoscopy versus convencional upper endoscopy for the diagnosis of esophageal varices: a prospective three-center pilot study. Endoscopy 2006; 38(1): $31-5$

38. Koslowsky B, Jacob H, Eliakim R, Adler SN. PillCam ESO in esophageal studies: improved diagnostic yield of 14 frames per second (fps) compared with 4 fps. Endoscopy 2006; 38: 27-30.

39. Velayos B, Fernández L, Aller R, De La Calle F, Del Olmo L, Arranz T, González JM. Estudio de los tiempos intestinales con cápsula endoscópica. Gastroenterol Hepatol 2005; 28 (6): 315-20.

40. Fernández-Urién I, Espinet E, Pérez N, Betés M, Herráiz M, Carretero $\mathrm{C}$, et al. Interpretación de la cápsula endoscópica: el papel del personal no especializado. Rev Esp Enferm Dig 2008; 100(4): 21924.

41. Kitiyara T, Selby W. Non-small-bowel lesions detected by capsule endoscopy in patients with obscure GI Bleeding. Gastrointest Endosc 2005; 62(2): 234-8.

42. Edery J, Maniere T, Jian R, Cellier C. Diagnostic of missed upper and lower GI lesions outside the small intestine by video capsule endoscopy. In: 5th International Conference on Capsule Endoscopy. París; 2006 (abstract)

43. Matas JL, Asteinza M, Loscos JM, Fernández S, Ramírez-Armengol JA, Díaz-Rubio M. Rendimiento diagnóstico y seguridad de la cápsula endoscópica. Rev Esp Enferm Dig 2006; 98(9): 666-73.

44. Caunedo A, Rodríguez-Téllez M, Gómez-Rodríguez BJ, García Montes JM, Guerrero J, Herrerías JM, et al. Utilidad de la cápsula endoscópica en pacientes con sospecha de patología de intestino delgado. Rev Esp Enferm Dig 2004; 96(1): 10-21.

45. Makins R, Blanshard C. Guidelines for capsule endoscopy: diagnosis will be missed. Aliment Pharmacol Ther 2006; 24(2): 293-7.

46. Lewis B, Goldfarb N. The advent of capsule endoscopy -a not so futuristic approach to obscure gastrointestinal bleeding. Aliment Pharmacol Ther 2003; 17(9): 1085-96.

47. Pennazio M, Santucci R, Rondonotti E, Abbiati C, Beccari G, Rossini FP, et al. Outcome of patients with obscure gastrointestinal bleeding after capsule endoscopy: report of 100 consecutive cases. Gastroenterology 2004: 126(3): 643-53. 